I N S T I T U T O

$\mathrm{DE}$

M E D I C I N A

T R O P I C A L

DE

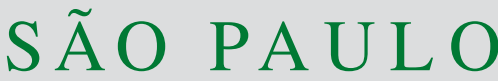

JOURNAL OF THE SÃO PAULO INSTITUTE OF TROPICAL MEDICINE

${ }^{1}$ Grupo Hospitalar Conceição, Hospital Nossa Senhora da Conceição, Unidade de Terapia Intensiva Adulto, Porto Alegre, Rio Grande do Sul, Brazil

${ }^{2}$ Universidade Federal de Ciências da Saúde de Porto Alegre, Porto Alegre, Rio Grande do Sul, Brazil

${ }^{3}$ Grupo Hospitalar Conceição, Programa de Pós-Graduação em Avaliação de Tecnologias para o Sistema Único de Saúde, Porto Alegre, Rio Grande do Sul, Brazil

Correspondence to: Veridiana Baldon dos Santos

Grupo Hospitalar Conceição, Hospital Nossa Senhora da Conceição, Unidade de Terapia Intensiva Adulto, Rua Francisco Trein, 596, CEP 91350-200, Porto Alegre, RS, Brazil

Tel: +555133572000

E-mail: veridbaldon@ @otmail.com

Received: 18 November 2021

Accepted: 27 January 2022

\section{Adult patients admitted to a tertiary hospital for COVID-19 and risk factors associated with severity: a retrospective cohort study}

\author{
Veridiana Baldon dos Santos ${ }^{\circledR 1}$, Airton Tetelbom Stein ${ }^{\circledR 2,3}$, Sofia Louise \\ Santin Barilli ${ }^{\circledR}$, Andresa Fontoura Garbini ${ }^{(1}$, Rafaela Charão de Almeida ${ }^{\left({ }^{1}\right.}$, \\ Daniela dos Reis Carazai ${ }^{(1)}$, Fernanda Costa dos Santos ${ }^{\circledR 1}$, Raquel \\ Lutkmeier $^{(1)}$, Isadora Helena Greve ${ }^{(1)}$, André Klafke ${ }^{\left({ }^{3}\right.}$, Ketlen Monteiro \\ Mussart $^{\circledR 1}$, Estefania Inez Wittke ${ }^{\circledR 3}$
}

\section{ABSTRACT}

COVID-19 is a disease whose knowledge is still under construction, high transmissibility, with no consensual treatment available to everyone. Therefore, the identification of patients at higher risk of evolving to the critical form of the disease is fundamental. The study aimed to determine risk factors associated with the severity of COVID-19 in adults patients. This is an observational, retrospective study from a cohort of adult patients with COVID-19 admitted to a public hospital from March to August 2020, whose medical records were evaluated. For the association of possible severity predictors, a Poisson regression was used. The primary outcome was the critical form of the disease (need for admission to the Intensive Care Unit and/or invasive mechanical ventilation). We included 565 patients: mostly men; $55.5 \%$ of those who progressed to the critical form of the disease were over sixty years old. Hypertension, diabetes mellitus and obesity were the most frequent comorbidities. There were $39.8 \%$ of patients who progressed to the critical form of the disease. The hospital mortality rate was $22.1 \%$, and that of critical patients was $46.7 \%$. The independent factors associated with the severity of the disease were obesity $[R R=1.33(95 \%$ CI 1.07 to $1.66 ; p=0.011)]$, $\mathrm{SpO}_{2} / \mathrm{FiO}_{2}$ ratio $\leq 315[\mathrm{RR}=2.20(95 \% \mathrm{CI} 1.79$ to $2.71 ; \mathrm{p}=0.000)]$, C-reactive protein $>$ $100 \mathrm{mg} / \mathrm{L}[\mathrm{RR}=1.65(95 \% \mathrm{CI} 1.33$ to $2.06 ; \mathrm{p}=0.000)]$, and lymphocytes $<1,000 / \mu \mathrm{L}$ $[R R=1.44(95 \% \mathrm{CI} 1.18$ to $1.75 ; \mathrm{p}=0.000)]$. Advanced age and comorbidities were dependent factors strongly associated with the critical form of the disease.

KEYWORDS: COVID-19. SARS-CoV-2. Risk factors. Severity. Cohort study.

\section{INTRODUCTION}

COVID-19 caused a sudden and substantial global increase in hospitalizations and mortality due to severe acute respiratory syndrome ${ }^{1}$. The flu-like syndrome, transmitted primarily through the respiratory $\operatorname{tract}^{2}$ by asymptomatic, presymptomatic and symptomatic carriers ${ }^{1}$, has heterogeneous clinical symptomatology, varying from asymptomatic to mild symptoms up to serious/critical cases ${ }^{1,3}$.

The critical form of the disease consists of a severe acute respiratory syndrome (SARS) defined by hypoxemia that requires invasive mechanical ventilation (MV) ${ }^{4}$. Severe COVID-19 generally involves respiratory manifestations, although other systems can also affected. The critical form of the disease is usually followed by long term complications ${ }^{5}$. 
Currently, COVID-19 is responsible for millions of cases and deaths worldwide ${ }^{1}$. The Brazilian Unified Health System (SUS), a global reference of universal health care ${ }^{6}$, is fundamental for meeting the demands of the pandemic in the country, however, it has also faced difficulties. The beginning of 2021 was marked by the second wave of COVID-19 in Brazil, which presented characteristics that differed from the first wave ${ }^{7}$. The substantial increase in COVID-19 cases in different regions of the country caused a huge pressure on the health system, which was already overloaded after one year of pandemic and the likely dominance of new variants ${ }^{8}$.

The clinical characteristics of patients with COVID-19 and the severity of the illness may vary between studies in different regions ${ }^{1,9}$. We still do not know how the pandemic will behave, therefore, promoting an observational study on patients hospitalized with COVID-19 in a public reference hospital in Southern Brazil represents an opportunity for the early identification of the worst outcomes related to COVID-19, in addition to guiding decision-making to reduce intra-hospital mortality. The study aimed to determine risk factors associated with the severity of COVID-19 in adult patients.

\section{MATERIALS AND METHODS}

This is an observational, retrospective study from a cohort of adult patients with COVID-19 admitted to a large high-complexity tertiary public hospital ${ }^{10}$ from March 1 to August 20, 2020, whose medical records were evaluated. Data were collected in the context of the multicentric study "National multicentric hospital record of patients with disease caused by SARS-CoV-2 (COVID-19)" conducted by the Federal University of Minas Gerais, Minas Gerais State, Brazil.

The eligible medical records belong to patients with COVID-19 diagnosis confirmed by RT-PCR or serology, who were admitted by spontaneous demand, were transferred or referred to our hospital by another service. Patients admitted to the institution for other reasons or who acquired COVID-19 during hospitalization, pregnant women and patients with COVID-19 diagnosis confirmed by other methods than RT-PCR and serology were deemed ineligible.

Data were collected at admission, during hospitalization and at the time of the disease outcome. The variables collected at admission (first $24 \mathrm{~h}$ ) were related to the diagnostic method for COVID-19, demographic and clinical characteristics, previous health history, laboratory test results and imaging exams. During hospitalization, the following variables were described: drug therapy, vasoactive amines, prone position, non-invasive ventilation (NIV) at any moment, need for renal replacement therapy (RRT), and main complications during hospitalization. Among the clinical outcomes, we collected information on admission to the ICU, need for MV, hospital discharge or death. The primary outcome was the development of the critical form of the disease, characterized by admission to the ICU and/or need for MV.

Data were collected from July to December 2020 from electronic medical records and entered, according to a standardized protocol, in the online platform Research Electronic Data Capture - REDCap ${ }^{\circledast}$. Clinical data were submitted to a univariate analysis; for the variables of interest at hospital admission, during hospitalization, and at the time of the study outcome, the reference values and measurement units of the tests followed the manufacturers' instructions. The $\mathrm{SpO}_{2} / \mathrm{FiO}_{2}$ ratio was calculated using data from the hospital admission on peripheral oxygen saturation $\left(\mathrm{SpO}_{2}\right)$ and oxygen flow in liters per minute $(\mathrm{L} / \mathrm{min})$ for patients in spontaneous ventilation. The oxygen flow was converted into the approximate fraction of inspired oxygen $\left(\mathrm{FiO}_{2}\right)$ : no device - ambient air (0.21); nasal cannula $1(0.24) 2$ (0.28) 3 (0.32) 4 (0.36) 5 (0.40) 6 (0.44); simple mask (0.40) $6(0.50) 7$ (0.60); mask with reservoir 6 (0.60) 7 (0.70) 8-9 (0.80) 10-15 (0.95). For patients under NIV/MV, the $\mathrm{FiO}_{2}$ described in the medical record was considered.

Continuous variables were expressed in medians and interquartile intervals (IQI), whereas categorical variables were expressed as absolute and relative frequencies. To compare the clinical complications during hospitalization of critical and non-critical patients, the Pearson chi-square test was used. The association of possible predictors with the severity outcome was carried out through the robust Poisson regression model for the estimate of prevalence ratios and 95\% confidence intervals (CIs). In the multivariate analysis, a missing data percentage of $8.8 \%$ was considered for the inclusion of variables. Significant variables were selected and included in the multivariate model (age 60 to 69 ; age $\geq 70 ; \mathrm{SpO}_{2} / \mathrm{FiO}_{2}$ ratio $\leq 315$; hypertension; diabetes mellitus; obesity (BMI $\left.>30 \mathrm{~kg} / \mathrm{m}^{2}\right)$; malignant neoplasia; C-reactive protein $>100$ $\mathrm{mg} / \mathrm{L}$; lymphocytes $<1,000 / \mu \mathrm{L}$; urea $>50 \mathrm{mg} / \mathrm{dL}$; use of vasoactive amines upon admission and altered level of consciousness upon admission). $P$-values of 0.05 or less were considered statistically significant. We excluded variables with missing data due to the high risk of bias, possibly not representing the population adequately. No other form of data entry was used. All analyses were carried out with the software SPSS Statistics version 20.0 (IBM Corporation, Armonk, NY, USA). 
As data were collected from medical records, the free and informed consent form was waived. The study was approved by the local Research Ethics Committee and the National Research Ethics Commission under the number CAAE 30350820.5.0000.0008.

\section{RESULTS}

The population was initially composed of 604 patients; 30 already hospitalized for other reasons, who contracted the virus during hospitalization were excluded, in addition to nine pregnant women. In the most critical period of the pandemic, 63 patients who did not require a high level of medical care were transferred to hospitals for less complex cases to continue their treatment, while two critical patients were transferred to another reference hospital due to lack of vacancy in the ICU. Information on their health outcomes was collected from the medical records of the institutions that took care of them. Therefore, 565 patients were included in the analysis.

The diagnostic method to confirm COVID-19 was the RT-PCR test for $94.3 \%$ (533) of the patients. Men represented $52.9 \%$ (299) of the sample, with an average age of 58 years (IQI 45 to 67). Patients over 60 years old progressed more often to the critical form of the disease [relative risk $(\mathrm{RR})=1.46(95 \% \mathrm{CI} 1.15$ to 1.85$)$ ]. Likewise, there was no significant difference between genders. Demographic and clinical characteristics upon hospital admission in addition to laboratory and imaging tests results are shown in Table 1.

Regarding the health history of the patients, it was evinced that the average number of associated comorbidities was higher among those who presented with the worst prognoses. Patients with more comorbidities progressed to

Table 1 - Demographic characteristics, previous health history, clinical data, laboratory and imaging tests results upon hospital admission.

\begin{tabular}{lc}
\hline Variable & $\begin{array}{c}\text { Total }-\mathrm{N}(\%) / \\
\mathrm{N}=595\end{array}$ \\
\hline Gender & \\
Male & $299(52.9)$ \\
Age (years) & \\
$<60$ & $303(53.6)$ \\
61 to 69 & $135(23.9)$ \\
$>70$ & $127(22.5)$ \\
Most frequent comorbidities & \\
Hypertension & $265(46.9)$ \\
Diabetes mellitus & $163(28.8)$ \\
Obesity & $90(15.9)$ \\
Asthma & $47(8.3)$ \\
COPD & $47(8.3)$ \\
Neoplasia & $44(7.8)$ \\
Coronary artery disease & $42(7.4)$ \\
Chronic kidney disease & $35(6.2)$ \\
Living Habits & \\
Use of illicit drugs & $10(1.8)$ \\
Alcoholism & $28(5.0)$ \\
Current smoking & $33(5.8)$ \\
Formersmoker & $114(20.2)$ \\
Most prevalent clinical manifestations & \\
Dyspnea & $372(65.8)$ \\
Fever & $329(58.2)$ \\
Dry cough & $299(52.9)$ \\
Myalgia & $189(33.5)$ \\
Adynamia & $133(23.5)$ \\
Anosmia (loss of smell) & $99(17.5)$ \\
Headache & $99(17.5)$ \\
Clinical alterations upon hospital & \\
Adtered level of consciousness & \\
BP $90 / 60$ mmHg & \\
\hline & \\
\hline
\end{tabular}

\begin{tabular}{|c|c|}
\hline Variable & $\begin{array}{c}\text { Total - N (\%) / } \\
N=595\end{array}$ \\
\hline Vasoactive amines & $30(5.3)$ \\
\hline $\mathrm{HR} \geq 100 \mathrm{bpm}$ & $145(30.9)$ \\
\hline $\mathrm{RRt} \geq 20$ mipm & $240(56.5)$ \\
\hline $\operatorname{Tax} \geq 37.8^{\circ} \mathrm{C}$ & $106(27.5)$ \\
\hline $\mathrm{SpO} 2<93 \%$ & $115(21.1)$ \\
\hline SpO2/FiO2 Ratio $\leq 315$ & $115(21.1)$ \\
\hline Supplemental $\mathrm{O}_{2}$ requirement & $206(36.5)$ \\
\hline \multicolumn{2}{|l|}{$\begin{array}{l}\text { Laboratory and imaging test results } \\
\text { upon admission }\end{array}$} \\
\hline C-Reactive Protein > $100 \mathrm{mg} / \mathrm{L}$ & $249(45.9)$ \\
\hline D-dimer $\geq 1,000 \mathrm{ng} / \mathrm{mL}$ FEU & $254(49.1)$ \\
\hline Platelets $\leq 15,0000 / u L$ & $79(14.5)$ \\
\hline Lactate $(A B G) \geq 1.6 \mathrm{mmol} / \mathrm{L}$ & $137(26.9)$ \\
\hline Troponin $\geq 14 \mathrm{ng} / \mathrm{L}$ & $171(40.9)$ \\
\hline Lymphocytes < 1,000/uL & $235(42.0)$ \\
\hline Urea $\geq 50 \mathrm{mg} / \mathrm{dL}$ & $154(27.2)$ \\
\hline Creatinine $>1.2 \mathrm{mg} / \mathrm{dL}$ & $144(25.8)$ \\
\hline GOT/AST $\geq 37 \mathrm{U} / \mathrm{L}$ & $248(60.6)$ \\
\hline $\mathrm{GPT} / \mathrm{ALT} \geq 41 \mathrm{U} / \mathrm{L}$ & $165(40.6)$ \\
\hline INR $\geq 1.3$ & $116(25.3)$ \\
\hline $\mathrm{pO}_{2}(\mathrm{ABG})<83 \mathrm{mmHg}$ & $351(70.5)$ \\
\hline Hemoglobin $<12.8 \mathrm{~g} / \mathrm{dL}$ & $201(36.0)$ \\
\hline Chest x-ray & $535(94.7)$ \\
\hline Altered x-ray & $434(81.1)$ \\
\hline Chest CT & $101(17.9)$ \\
\hline Altered chest CT & $96(95.0)$ \\
\hline Involvement $>25 \%$ of lung parenchyma & $30(65.2)$ \\
\hline \multicolumn{2}{|c|}{$\begin{array}{l}\text { Frequency (percentage) or median (interquartile interval) } \\
\mathrm{BP}=\text { blood pressure; } \mathrm{HR}=\text { heart rate; } \mathrm{RRt}=\text { respiratory rate } \\
\mathrm{Tax}=\text { axillary temperature; } \mathrm{SpO} 2=\text { peripheral oxygen saturation } \\
\mathrm{SpO} 2 / \mathrm{FiO} 2 \text { ratio = the ratio between the peripheral oxyger } \\
\text { saturation and the fraction of inspired oxygen; } \mathrm{ABG}=\text { arteria } \\
\text { blood gas; } \mathrm{CT}=\text { computerized tomography. }\end{array}$} \\
\hline
\end{tabular}


the critical form of the disease up to twice as often (Table 2). Just over half of the patients $(51.5 \%, 291)$ presented with some associated cardiovascular disease and $46.4 \%$ (135) of them were admitted to the ICU or required MV. Oncology patients progressed to the critical form of the disease nearly twice as often $[R R=1.41$ (1.05 to 1.90)]. The most prevalent comorbidities were systemic hypertension, diabetes mellitus (DM) and obesity. Comorbidities behave as age-dependent factors - the older the individual, the greater the number of associated preexisting diseases. Chronic kidney disease
(CKD) was not associated with the severity of COVID-19. Respiratory system diseases such as asthma and chronic obstructive pulmonary disease (COPD) proved to behave as protective variables for the severity ofCOVID-19.

In $15.9 \%$ (90) of the patients, obesity was characterized as an independent variable for the severity of COVID-19. Hospitalized obese patients were on average 49 years old (IQI 23 to 84), 62.2\% (56), presented with two or more comorbidities and $52.5 \%$ (47) were admitted to the ICU. The mortality rate among obese patients was $17.8 \%$ (16),

Table 2 - Significant variables for the severity of the patients admitted due to COVID-19 in the bivariate analysis.

\begin{tabular}{|c|c|c|c|}
\hline Variable & $\begin{array}{c}\text { ICU/MV } \\
N(\%) \\
N=225(39.8) \\
\end{array}$ & $\mathrm{RR}(95 \% \mathrm{Cl})$ & $P$-value \\
\hline \multicolumn{4}{|l|}{ Age (years) } \\
\hline$<60$ & $100(33.0)$ & 1 & \\
\hline 61 to 69 & $65(48.1)$ & 1.46 (1.15 to 1.85$)$ & 0.004 \\
\hline$>70$ & $60(47.2)$ & $1.43(1.12$ to 1.83$)$ & 0.002 \\
\hline \multicolumn{4}{|l|}{ Comorbidities } \\
\hline Hypertension & $122(46.0)$ & 1.34 (1.09 to 1.64$)$ & 0.005 \\
\hline Diabetes mellitus & $78(47.9)$ & $1.31(1.07$ to 1.61$)$ & 0.010 \\
\hline Obesity & 48 (53.3) & $1.43(1.14$ to 1.79$)$ & 0.002 \\
\hline Neoplasia & $24(54.5)$ & 1.41 (1.06 to 1.89$)$ & 0.020 \\
\hline \multicolumn{4}{|l|}{ Number of comorbidities } \\
\hline None & $46(26.3)$ & 1 & \\
\hline 1 & $70(42.7)$ & $1.62(1.20$ to 2.20$)$ & 0.002 \\
\hline$\geq 2$ & $109(48.2)$ & 1.84 (1.38 to 2.43 ) & $<0.001$ \\
\hline \multicolumn{4}{|l|}{ Clinical alterations upon admission } \\
\hline Altered level of consciousness & $45(70.3)$ & 1.96 (1.61 to 2.38$)$ & $<0.001$ \\
\hline Vasoactive amines & $29(96.7)$ & 2.64 (2.32 to 3.00$)$ & $<0.001$ \\
\hline $\mathrm{SpO}_{2}<93 \%$ & $82(71.3)$ & 2.21 (1.85 to 2.65$)$ & $<0.001$ \\
\hline $\mathrm{SpO}_{2} / \mathrm{FiO}_{2}$ Ratio $\leq 315$ & $97(84.3)$ & 2.93 (2.48 to 3.47 ) & $<0.001$ \\
\hline Supplemental $\mathrm{O}_{2}$ requirement & $130(63.1)$ & 2.39 (1.95 to 2.92$)$ & $<0.001$ \\
\hline \multicolumn{4}{|l|}{ Laboratory and imaging tests upon admission } \\
\hline C-Reactive Protein $>100 \mathrm{mg} / \mathrm{L}$ & $141(56.6)$ & 2.13 (1.71 to 2.66$)$ & $<0.001$ \\
\hline Lactate $(A B G) \geq 1.6 \mathrm{mmol} / \mathrm{L}$ & $74(54.0)$ & $1.44(1.17$ to 1,76$)$ & $<0.001$ \\
\hline Troponin $\geq 14 \mathrm{ng} / \mathrm{L}$ & $92(53.8)$ & $1.58(1.27$ to 1.98$)$ & $<0.001$ \\
\hline Lymphocytes $<1,000 / \mathrm{Ul}$ & $123(52.3)$ & $1.70(1.38$ to 2.08$)$ & $<0.001$ \\
\hline Urea $\geq 50 \mathrm{mg} / \mathrm{dL}$ & $83(53.9)$ & 1.55 (1.27 to 1.90$)$ & $<0.001$ \\
\hline Creatinine $>1.2 \mathrm{mg} / \mathrm{dL}$ & $76(52.8)$ & $1.48(1.21$ to 1.81$)$ & $<0.001$ \\
\hline GOT/AST $\geq 37 \mathrm{U} / \mathrm{L}$ & $106(42.7)$ & $1.32(1.01$ to 1.73$)$ & 0.039 \\
\hline INR $\geq 1.3$ & $64(55.2)$ & $1.44(1.17$ to 1.78$)$ & 0.001 \\
\hline Altered chest $x$-ray & $189(43.5)$ & 2.00 (1.36 to 2.94$)$ & $<0.001$ \\
\hline Need of NIV at some time during hospitalization & $21(87.5)$ & $2.32(1.93$ to 2.80$)$ & $<0.001$ \\
\hline
\end{tabular}

Frequency (percentage); $\mathrm{RR}=$ Relative risk; $\mathrm{Cl}=$ Confidence interval; $\mathrm{O}_{2}=$ oxygen; $\mathrm{SpO}_{2}=$ peripheral oxygen saturation; $\mathrm{SpO}_{2} / \mathrm{FiO}_{2}$ Ratio = the ratio between the peripheral oxygen saturation and the fraction of inspired oxygen; $\mathrm{ABG}=$ arterial blood gas; NIV = non-invasive ventilation. 
with the acute respiratory distress syndrome (ARDS) as the primary complication associated with severity $(23.3 \%$, 21).

Predominant symptoms upon hospital admission were dyspnea, fever, dry cough and myalgia (Table 1). The mean time from the beginning of the symptoms until hospital admission was seven days (IQI 3 to 10) for non-critical patients and five days (IQI 2 to 7 ) for patients who required ICU and/or MV. However, the symptoms did not prove to be statistically significant to discriminate the severity of the outcome.

On admission, clinical manifestations that proved to be significantly associated with the critical form of the disease are shown in Table 2. In the multivariate analysis, we used the $\mathrm{SpO}_{2} / \mathrm{FiO}_{2}$ ratio $[\mathrm{RR}=2.93$ (2.48 to 3.47)] instead of the isolated $\mathrm{SpO}_{2}[\mathrm{RR}=2.21$ (1.85 to 2.65) $]$ because there was a higher relative risk for severity of COVID-19. Among the patients who presented with $\mathrm{SpO}_{2} / \mathrm{FiO}_{2}$ ratios $\leq 315$ upon admission, $84.3 \%$ (97) were admitted to the ICU or required MV.

Critically ill patients had lower lymphocyte counts, higher serum levels of troponin, international normalized ratio (INR), creatinine, urea, glutamic oxaloacetic transaminase/aspartate aminotransferase (GOT/AST), C-reactive protein (CRP) and arterial blood gas (ABG) lactate (Table 2). Despite showing a significant association with severity $(p<0.001)$, troponin was not included in the multivariate analysis due to the absence of available data. Likewise, GOT/AST, a significant variable for the severity of the illness $(p=0.039)$, was altered in more than $60.6 \%$ (248) of the samples collected upon admission, even so with a high rate of lost data. The chest $\mathrm{x}$-rays upon admission were altered in $81.1 \%$ (434) of the patients. The main alterations were the presence of diffuse infiltrates in $36.3 \%$ (194), opacities in $28.2 \%$ (151) and consolidations in $23 \%$ (123). Altered chest $\mathrm{x}$-rays upon admission were associated with the critical form of the disease $[R R=2.00$ (1.36 to 2.94)] (Table 2).
During hospitalization due to COVID-19, 39.8\% (225) of the patients progressed to the critical form of the disease and $36.8 \%$ (208) were admitted to the ICU, 35.9\% (203) progressing to MV, $11.7 \%$ (66) needing RRT (10 were already dialysis patients before hospitalization), $31.7 \%$ (179) received vasoactive amines, $18.9 \%$ (107) required the prone position and $4.2 \%$ (24) used NIV at some point during hospitalization. The average duration of MV in the patients was 11 days (IQI 7 to 21). The main clinical complications related to the severity of COVID-19 during hospitalization are shown in Table 3.

Eighty-three patients were admitted to the ICU, and other 17 could not find an ICU vacancy in the institution. The average age of these 17 patients was 73 years (IQI 58 to 80 ). The hospital mortality rate was $22.1 \%$ (125) and among critically ill patients it was $46.7 \%$ (105). Regarding the patients admitted to the ICU, 49.3\% (100) required MV and $42.3 \%$ (88) died. Three patients died within the first six hours of their admission, eight patients kept waiting for ICU beds in the emergency department until their deaths were confirmed, and four patients progressed to palliative care after the aggravation of COVID-19. The mortality of patients not admitted to the ICU was $100 \%$.

The average hospitalization time was nine days (IQI 5 to 17). The average hospitalization time was 19 days for critically ill patients, (IQI 11 to 30), and the average ICU stay was 12 days (IQI 7 to 23). For non-critical patients, the average hospitalization time was six days (IQI 4 to 9).

In the multivariate Poisson regression model (Table 4), some factors were independently associated with a higher risk of COVID-19 severity: obesity [RR $=1.48$ (95\% CI 1.19 to 1.84)], $\mathrm{SpO}_{2} / \mathrm{FiO}_{2}$ ratio $\leq 315$ upon admission $[R R=2.20(95 \%$ CI 1.79 to 2.71$)], C R P>100 \mathrm{mg} / \mathrm{L}$ upon admission [RR $=1.73$ (95\% CI 1.40 to 2.15)], and lymphocytes $<1,000 / \mathrm{uL}$ upon admission $[\mathrm{RR}=1.40(95 \%$ CI 1.15 to 1.70$)$ ].

Table 3 - Main clinical complications during the hospitalization of patients with COVID-19.

\begin{tabular}{|c|c|c|c|c|}
\hline & $\begin{array}{c}\text { Sample } \\
(n=565)\end{array}$ & $\begin{array}{c}\text { Critical } \\
(n=225)\end{array}$ & $\begin{array}{c}\text { Non-critical } \\
(n=340)\end{array}$ & $P$-value \\
\hline ARDS & $98(17.3)$ & $95(42.2)$ & $3(0.9)$ & $<0.001$ \\
\hline Nosocomial infection & $94(16.6)$ & $82(36.4)$ & $12(3.5)$ & $<0.001$ \\
\hline Septic shock & $86(15.2)$ & $82(36.4)$ & $4(1.2)$ & $<0.001$ \\
\hline Hyperglycemia & $88(15.6)$ & $68(30.2)$ & $20(5.9)$ & $<0.001$ \\
\hline Pulmonary thromboembolism & $40(7.1)$ & 29 (12.9) & $11(3.2)$ & $<0.001$ \\
\hline Peripheral venous thrombosis & $13(2.3)$ & $12(5.3)$ & $1(0.3)$ & $<0.001$ \\
\hline Hemorrhage & $11(1.9)$ & $10(4.4)$ & $1(0.3)$ & $<0.001$ \\
\hline
\end{tabular}

Frequency (percentage); $P=$ Pearson chi-square test; ARDS = Acute respiratory distress syndrome. 
Table 4 - Independent variables for severity in patients with COVID-19.

\begin{tabular}{lcc}
\hline \multirow{2}{*}{ Variable } & Multivariable & \\
\cline { 2 - 3 } & $\mathrm{RR}(95 \% \mathrm{Cl})$ & $<$-value \\
\hline Obesity & $1.48(1.19$ to 1.84$)$ & $<.001$ \\
$\mathrm{SpO}_{2} / \mathrm{FiO}_{2}$ Ratio $\leq 315$ & $2.20(1.79$ to 2.71$)$ & $<0.001$ \\
Lymphocytes $<1,000 / \mathrm{uL}_{\text {C-Reactive Protein }>100 \mathrm{mg} / \mathrm{L}}^{1.40(1.15 \text { to } 1.70)}$ & $<0.001$ \\
\hline
\end{tabular}

$\mathrm{RR}=$ Relative risk; $\mathrm{Cl}=$ confidence interval; $P=$ multivariate Poisson regression model.

\section{DISCUSSION}

In the present study, patients over 60 years old had nearly twice the risk of developing the critical form ofCOVID-19. Comorbidities behave as an age-dependent factor. Half of the patients reported associated cardiovascular diseases, and half of them were admitted to the ICU. Two or more preexisting comorbidities were present in $40 \%$ of the patients and showed a significant association with worse outcomes. Obesity was an independent variable for the severity of the illness. Patients with $\mathrm{SpO}_{2} / \mathrm{FiO}_{2}$ ratios $\leq 315$ upon admission were up to three times more often admitted to the ICU or required MV. Lower lymphocyte counts and higher CRP levels upon admission were independent factors for the critical form of the disease and altered chest $\mathrm{X}$-rays upon admission and the use of NIV at some point during hospitalization were also associated with unfavorable outcomes. Four in every ten patients with COVID-19 presented with the critical form of the illness.

Most of the patients $(94.3 \%, 533)$ were diagnosed by a positive reverse transcription polymerase chain reaction (RT-PCR) amplification, which, according to Kumar et $a l .{ }^{11}$, is still the gold standard for diagnosing COVID-19.

The results of this study demonstrated that patients over 60 years old with associated comorbidities had worse COVID-19 prognosis, as in the study by Li et al. ${ }^{12}$, Schuelter-Trevisol et al. ${ }^{13}$ and Tan et al. ${ }^{14}$. In the systematic review by Tan et al. ${ }^{14}$, critically ill patients with COVID-19 had an average age of 62.6 years. Our findings agree with the evidence found in several studies that pointed out a more significant occurrence of the critical form of the disease in older patients ${ }^{15-19}$. The decreased cardiopulmonary reserve in old patients increases the risk of complications, and the aging of the immune system (immunosenescence), leads to a pro-inflammatory trend, contributing to an exacerbated response to SARS-CoV-2 $2^{16,20}$.

However, in this study, the age factor did not prove to be independently associated with a more serious outcome. This finding may suggest that the use of a criterion of age for the prioritization of patients in cases of a scarcity of
ICU beds, is not the most appropriate considering that other criteria can be evaluated concomitantly such as the existence of associated comorbidities, the irreversible impairment of cognitive functions and the application of fragility scales, according to screening guidelines in catastrophe situations and the particularities of the COVID-19 pandemic by $\mathrm{AMIB}^{2}$. Recent systematic reviews ${ }^{12,21}$ have identified results similar to ours, in which the most associated comorbidities with severity were diseases of the cardiovascular system, with a higher prevalence of systemic hypertension. According to Liang et al. ${ }^{22}$, a cancer history proved to be an independent factor in their study. A systematic review with 16,561 critically ill patients in 17 countries and four continents identified that advanced age and comorbidities such as obesity, systemic hypertension, DM and cardiovascular diseases were the main risk factors for severe COVID-19 12 .

This study suggests that the higher the number of preexisting comorbidities, the higher the risk of developing the critical form of the disease, in agreement with the results by Cheng et $a l .{ }^{23}$, Suleyman et $a l .{ }^{24}$, and Giri et al. ${ }^{25}$. In Brazil, one in every five Brazilian adults has two or more comorbidities $^{26}$. A study in Sergipe, in Northeastern Brazil, pointed out a mortality 1.5 times higher associated with systemic hypertension or DM in patients over 65 years old $^{26}$. The study by Li et al. ${ }^{12}$ suggested that patients with subjacent diseases are more vulnerable to pneumonia and have weaker immunity systems and a higher probability of falling seriously ill. The effects of SARS-CoV-2 on the immune system, $\mathrm{T}$ cells and on the production of cytokines seem to further aggravate the pro-inflammatory trend in patients with cardiovascular comorbidities ${ }^{16,20}$. Andrade et $a{ }^{27}$ analyzed data from public Brazilian hospitals and identified that the behavior of the Charlson and Elixhauser indices (comorbidity assessment indices) was consistent with the hypothesis of a higher risk of the critical form of the disease and death by COVID-19 in patients with comorbidities, with obesity as an independent factor.

Similarly, in this cohort, the only comorbidity identified as an independent factor for severity of COVID-19 was 
obesity. A growing body of evidence suggests that obesity and the increase in visceral adiposity are strongly and independently associated with adverse outcomes, the critical form of the disease, and death due to COVID-1928. Some studies highlighted other characteristics of obesity such as alteration of respiratory mechanics, hampered pulmonary function and coexistence of metabolic disorders such as diabetes and cardiovascular diseases in a single individual that also increase the risk of severe COVID-1929. The main complication associated with the severity of the disease in obese individuals in this study was ARDS. Obesity itself is a comorbidity generally associated with other health problems; according to this study, $62.2 \%$ (56) of obese patients had two or more comorbidities. Although the mean age of the cohort patients was 49 years, according to Gonçalves et al..$^{30}$, the immunological imbalance in obesity does not depend on age to impair the response. Gonçalves et al. ${ }^{30}$ have also claimed that obesity is associated with an increase in ICU hospitalizations and a more considerable need for ventilation support in hospitalized obese patients, which we also identified in this study. Despite the greater need for ICUs and MV, the mortality was lower (17.8\%) in obese patients compared to the general mortality (22.1\%) due to COVID-19, which may be justified by the lower average age of obese patients, disagreeing with Gonçalves et $a l .{ }^{30}$. Obesity complicated their health conditions, but they died less for being younger and had more significant organic reserves. In the Brazilian National Vaccination Plan against COVID-19 $9^{31}$, obesity is only considered a comorbidity when it is morbid obesity (BMI $\geq 40$ ). However, according to this study, obese individuals with BMI $\geq 30$ are already in the risk group for the critical form of the disease, and it is important and necessary to take this finding into account.

This study has also identified clinical markers upon admission associated with the critical form of the disease, including the $\mathrm{SpO}_{2} / \mathrm{FiO}_{2}$ ratio, which proved to be an independent predictor factor associated with severity. We compared the clinical relevance with the severity of the patients' $\mathrm{SpO}_{2} / \mathrm{FiO}_{2}$ ratio, $\mathrm{SpO}_{2}$ and partial pressure of oxygen $\left(\mathrm{PaO}_{2}\right)$ of the $\mathrm{ABG}$ and identified the $\mathrm{SpO}_{2} / \mathrm{FiO}_{2} \leq 315$ as the best predictor for the critical form of the disease $\left[\mathrm{RR}=2.93\right.$ (2.48 to 3.47)]. The $\mathrm{SpO}_{2} / \mathrm{FiO}_{2}$ ratio is a low-cost, non-invasive, painless, quick and safe method available in most health services and a reliable predictor for ARDS, as described in the literature and corroborated in this study, becoming a differential method in facing the pandemic. The $\mathrm{PaO}_{2}$ of the ABG, even with hypoxemia, did not prove to be a significant factor for severity. In the study by Choi et al. ${ }^{32}$, the $\mathrm{SpO}_{2} / \mathrm{FiO}_{2}$ ratio upon admission presented an area under the receiver operating characteristic curve (ROC) around $85.7 \%$, characterizing the $\mathrm{SpO}_{2} / \mathrm{FiO}_{2}$ ratio as a strong predictor for the occurrence of ARDS. The $\mathrm{WHO}^{33}$ recommended the $\mathrm{SpO}_{2} / \mathrm{FiO}_{2}$ ratio when $\mathrm{PaO} 2$ is not available, considering values $\leq 315$ as suggestive of SARS, including non-ventilated patients. According to Catoire et al. ${ }^{34}$, the $\mathrm{SpO}_{2} / \mathrm{FiO}_{2}$ ratio may be a reliable tool to screen for hypoxemia in patients admitted to the emergency department, particularly during the COVID-19 pandemic. Considering the current pandemic scenario, in which there is a shortage of supplies and hospital overcrowding, studies aimed at predicting the factors associated with the severity of COVID-19 through fast, available low and low-cost methods are very relevant. In the analysis of biomarkers, low lymphocytes count and high CRP levels were independent risk factors for severity. According to Li et al. ${ }^{12}$, CRP is a common inflammation marker in COVID-19 with high RR in critical groups. According to their results, lymphopenia and high CRP were intimately associated with severe pneumonia. To Malik et al. ${ }^{35}$, CRP may be the most effective and sensitive marker in predicting the progression of COVID-19, suggesting that one of the pathophysiological signatures of COVID-19 could be the sustained inflammatory response and the cytokine storm, similar to those found in patients infected with SARS-CoV and MERS-CoV, and severe inflammation would lead to immunological impairment, liver, myocardial and kidney damages in addition to activation of coagulation.

Altered chest $\mathrm{x}$-ray upon admission was strongly associated with severity; these patients are almost three times more likely to be at risk than others, similar to the findings of a cohort that studied 1,590 patients ${ }^{22}$ in whom the chest $\mathrm{x}$-ray was an independent predictive factor included in the risk score for chest $\mathrm{x}$-ray abnormality. In 10 studies focused on chest $\mathrm{x}$-ray findings, bilateral infiltrates were observed in $72 \%$ of the patients ${ }^{14}$. These results evinced that radiological abnormalities are the most direct diagnostic method for severe pneumonia ${ }^{12}$.

The $\mathrm{WHO}^{33}$ recommends the balanced use of all non-invasive respiratory support strategies, justified by the insufficient evidence base. During the pandemic, the concern that such strategies could cause more damage to the patients has emerged, by means of late tracheal intubation that could exacerbate the lung injury; for health professionals who could acquire nosocomial infections and for health systems, due to the high level of oxygen demand to ventilate a high number of ventilated patients ${ }^{36}$. In this cohort, $4.2 \%$ (24) of the patients used NIV; among them, $87.5 \%$ (21) were admitted to the ICU and $83.3 \%$ (20) progressed to MV. The variable time was not assessed, therefore, we cannot tell in what moment the patients used these procedures during hospitalization. Considering that NIV was only recommended when negative pressure 
systems are available due to the risk of aerosolization, we can assume that many patients only used NIV admission to the ICU due to the availability of adequate conditions. Currently, a better conduction of the patients with NIV support has been reported ${ }^{37}$ facilitated by the availability of more considerable evidence, so that it is possible that some admissions to ICUs and use of MV could have been avoided in the past.

The need for MV in this cohort was 35.9\% (203), totaling $89.4 \%$ (186) of the patients admitted to the ICU. Suleyman et al..$^{24}$ reported that $80.8 \%$ of their critically ill patients required MV. These estimates are higher than those pointed out by a private hospital in the city of Sao Paulo in which MV was necessary in $65 \%$ of the ICU patients. In the systematic review by Tan et al. ${ }^{14}, 67.7 \%$ of the patients needed MV. Facing an unknown and very dynamic pandemic, medical protocols were updated quickly, and, initially, early intubation was indicated, that this procedure can perhaps justify this high percentage of $\mathrm{MV}$ at the institution.

The need for intensive treatment observed in the study was $36.8 \%$ (208), and this rate is higher than those found in the systematic review by Li et $_{\text {al. }}{ }^{38}$, who estimated a $23 \%$ rate of critical COVID-19. According to Suleyman et al. ${ }^{24}$, $39.7 \%$ of their patients needed ICU hospitalization in a New York hospital, similar to the percentage found in this study. In another hospital with similar characteristics ${ }^{13}, 29 \%$ of the patients needed to be admitted to the ICU; in a private hospital, the need for ICU hospitalization was $33 \%{ }^{8}$. Some factors are considered to be associated with the slightly superior percentage found in this study, such as factors related to the higher incidence of comorbidities in our patients because they are socioeconomically disadvantaged, being dependent on the Brazilian Unified Health System (SUS), therefore facing more significant challenges in getting medical care and treatments. Marcolino et al. ${ }^{15}$ corroborated that the average number of comorbidities was smaller in patients from private hospitals than in patients from public and mixed hospitals.

The ICU mortality in the study by El Aidaoui et al. ${ }^{39}$ in South Africa was $31.1 \%$, lower than that found in this study $(46.7 \%, 105)$. Wiersinga et al. ${ }^{1}$ described a lethality of $40 \%$ in patients admitted to ICUs. There was a marked heterogeneity in the global mortality rate for patients with COVID-19 admitted to ICUs and the average was $28 \%$, according to Tan et al. ${ }^{14}$.

In the 17 patients who needed MV but were not admitted to the ICU due to the lack of vacant beds, the mortality rate was $100 \%$. Even if the patients in this condition being only 17 with an average age of 73 years old, we can infer that the management of critically ill patients by teams not qualified for the work in the ICU environment may have influenced this unfavorable clinical outcome.

Regarding the intra-hospital mortality, the percentage found in this study was $22.1 \%$ (125), similar to that of the city of New York, with $21 \%{ }^{40}$ and slightly lower than that of the one found in the study carried out in Sergipe State, of $29.2 \%{ }^{26}$. Andrade et al. ${ }^{27}$ reported a $24.4 \%$ mortality and suggested that there was a wide variation in hospital mortality by COVID-19 in the many services belonging to the Brazilian Unified Health System (SUS), and these differences were associated with demographic and clinical factors, social inequality and differences in the infrastructure of the services and the quality of the healthcare provided. According to Marcolino et al. ${ }^{15}$, public and mixed hospitals presented with higher mortality rates than private hospitals ( $24.7 \%$ vs. $26.2 \%$ vs. $10.8 \%$, p < 0.001). In the systematic review by Tan et $a l .{ }^{14}$ assessed the mortality rates at a global scale, and the percentages varied from $23.4 \%$ to $33.0 \%$.

Among the limitations of this study, we highlight the data collection in a public hospital, which may represent only a specific and disadvantaged portion of the population. Moreover, this is a retrospective study. Important social determinants such as family income and education level were not collected. The absence of data on some variables upon hospital admission was also a limiting factor. We believe that the unavailable data could be related to the absence of hospital guidelines specific for COVID-19 at that time of the pandemic, and current protocols were heterogeneous and divergent. In addition, the level of control or decompensation of preexisting comorbidities was not measured. We used data from the patients' hospital admission to identify the factors associated with the severity of COVID-19; data referring to the period of hospitalization were also not considered.

The importance of this cohort stems from the need for rapid and effective identification of patients at higher risk of developing the critical form of the disease through simple and objective parameters upon hospital admission, allowing prioritizing care for such patients and directing clinical management. The early identification of such factors associated with severity is essential in the attempt to reduce ICU admissions and, consequently, the morbimortality. This study includes s many variables, and a thorough review of medical records enabled the reliability of the results. Moreover, all data were submitted to periodical audits. The patients were monitored from admission to hospital discharge or death. The outcome of the cases transferred to other institutions were included in the study as we performed an active search, and retrieved information on the clinical profile of patients and associated factors upon admission and the hospital outcomes. We employed a methodology based on STROBE, a quality tool widely 
used in cohort studies. The collected data and the obtained conclusions are important considering that there are few studies on the subject in Latin America and in Brazil, so they can serve as subsidies for the development of clinical guidelines and help the allocation of supplies, teams and public resources, as well as for future research.

\section{CONCLUSION}

The results of this study provide important data on patients with COVID-19 admitted to a public hospital, their clinical profile and factors associated with progression of the disease. The advanced age and subjacent comorbidities are dependent factors associated with the critical form of the disease, as much as altered chest $\mathrm{x}$-rays upon hospital admission and the need for NIV at some time during the hospitalization. The main clinical complication among the critically ill patients was ARDS. The following were identified as independent factors for the severity of the disease: obesity, the $\mathrm{SpO}_{2} / \mathrm{FiO}_{2}$ ratio $\leq 315, \mathrm{CRP}>100 \mathrm{mg} / \mathrm{L}$, and lymphocytes $<1,000 / \mu \mathrm{L}$ upon admission. We found easily measurable results even in small centers with limited healthcare resources. However, considering that the epidemic curve is dynamic and that associated factors may diverge among regions for various reasons, in addition to the discovery of new variants, constant studies on the profile of infected patients and factors associated with the severity of the disease are necessary.

\section{AUTHORS' CONTRIBUTIONS}

VBS: literature search, study design, data collection, data analysis, data interpretation, writing; EIW, ATS and SLSB: literature search, study design, data analysis, data interpretation, writing; AFG, RCA, DRC, FCS, RL, IHG and KMM: literature search and data collection; AK: data analysis, data interpretation and writing.

\section{REFERENCES}

1. Wiersinga WJ, Rhodes A, Cheng AC, Peacock SJ, Prescott HC. Pathophysiology, transmission, diagnosis, and treatment of Coronavirus disease 2019 (COVID-19): a review. JAMA. 2020;324:782-93.

2. Associação Brasileira de Medicina de Emergência. Coronavírus e medicina de emergência: recomendações para o atendimento inicial do médico emergencista pela Associação Brasileira de Medicina de Emergência (ABRAMEDE). [cited 2022 Jan 27]. Available from: https://www.amib.org.br/fileadmin/ user_upload/POSICIONAMENTO_ABRAMEDE_-_ CORONAVIRUS_-_03-_10032020.pdf
3. Guan WJ, Ni ZY, Hu Y, Liang WH, Ou CQ, He JX, et al. Clinical characteristics of Coronavirus disease 2019 in China. N Engl J Med. 2020;382:1708-20.

4. Grupo Força Colaborativa COVID-19 Brasil. Orientações sobre diagnóstico, tratamento e isolamento de pacientes com COVID-19. [cited 2022 Jan 27]. Available from: https:// www.amib.org.br/fileadmin/user_upload/amib/2020/abril/15/ Covid_-_Recomendac_a_o_Forc_a_Tarefa.pdf.pdf_1_.pdf

5. Osuchowski MF, Winkler MS, Skirecki T, Cajander S, ShankarHari M, Lachmann G, et al. The COVID-19 puzzle: deciphering pathophysiology and phenotypes of a new disease entity. Lancet Respir Med. 2021;9:622-42.

6. Minas Gerais. Secretaria de Estado de Saúde. SUS. [cited 2022 Jan 27]. Available from: https://www.saude.mg.gov.br/sus

7. Bastos LS, Ranzani OT, Souza TM, Hamacher S, Bozza FA. COVID-19 hospital admissions: Brazil's first and second waves compared. Lancet Respir Med. 2021;9:e82-3.

8. Faria NR, Mellan TA, Whittaker C, Claro IM, Candido DS, Mishra $\mathrm{S}$, et al. Genomics and epidemiology of the P.1 SARS-CoV-2 lineage in Manaus, Brazil. Science. 2021;372:815-21.

9. Goel S, Jain T, Hooda A, Malhotra R, Johal G, Masoomi R, et al. Clinical characteristics and in-hospital mortality for COVID-19 across the globe. Cardiol Ther. 2020;9:553-9.

10. Grupo Hospitalar Conceição. Quem somos. [cited 2022 Jan 27]. Available from: https://www.ghc.com.br/default. asp?idMenu=institucional\&idSubMenu=1

11. Kumar H, Fernandez CJ, Kolpattil S, Munavvar M, Pappachan JM. Discrepancies in the clinical and radiological profiles of COVID-19: a case-based discussion and review of literature. World J Radiol. 2021;13:75-93.

12. Li X, Xu Z, Wang T, Xu X, Li H, Sun Q, et al. Clinical laboratory characteristics of severe patients with coronavirus disease 2019 (COVID-19): a systematic review and meta-analysis. Clin Epidemiol Glob Health. 2021;9:184-90.

13. Schuelter-Trevisol F, Raimundo LJ, Soccas HD, Antunes AF, Mohr RL, Marcon CE, et al. Assessment of patients with Covid-19 hospitalized in southern Santa Catarina. Rev Soc Bras Med Trop. 2020;53:e20200579.

14. Tan E, Song J, Deane AM, Plummer MP. Global impact of Coronavirus disease 2019 infection requiring admission to the ICU: a systematic review and meta-analysis. Chest. 2021;159:524-36.

15. Marcolino MS, Ziegelmann PK, Souza-Silva MV, Nascimento IJ, Oliveira LM, Monteiro LS, et al. Clinical characteristics and outcomes of patients hospitalized with COVID-19 in Brazil: results from the Brazilian COVID-19 registry. Int J Infect Dis. 2021;107:300-10

16. Smorenberg A, Peters EJ, van Daele P, Nossent EJ, Muller M. How does SARS-CoV-2 targets the elderly patients?: a review on potential mechanisms increasing disease severity. Eur $\mathbf{J}$ Intern Med. 2021;83:1-5. 
17. Wirth R, Becker C, Djukic M, Drebenstedt C, Heppner HJ, Jacobs AH, et al. COVID-19 im Alter-Die geriatrische Perspektive. Z Gerontol Geriatr. 2021;54:152-60.

18. Watson A, Wilkinson TM. Respiratory viral infections in the elderly. Ther Adv Respir Dis. 2021;15:1753466621995050.

19. Córdova LD, Vega AP, Luján-Carpio E, Parodi JF, MoncadaMapelli E, Armacanqui-Valencia I, et al. Clinical characteristics of older patients with COVID-19: a systematic review of case reports. Dement Neuropsychol. 2021;15:1-15.

20. Vrints CJ, Krychtiuk KA, Van Craenenbroeck EM, Segers VF, Price S, Heidbuchel H. Endothelialitis plays a central role in the pathophysiology of severe COVID-19 and its cardiovascular complications. Acta Cardiol. 2021;76:109-24.

21. Hu J, Wang Y. The clinical characteristics and risk factors of severe COVID-19. Gerontology. 2021;67:255-66.

22. Liang W, Liang H, Ou L, Chen B, Chen A, Li C, et al. Development and validation of a clinical risk score to predict the occurrence of critical illness in hospitalized patients with COVID-19. JAMA Intern Med. 2020;180:1081-9.

23. Cheng S, Zhao Y, Wang F, Chen Y, Kaminga AC, Xu H. Comorbidities' potential impacts on severe and non-severe patients with COVID-19: a systematic review and metaanalysis. Medicine (Baltimore). 2021;100:e24971.

24. Suleyman G, Fadel RA, Malette KM, Hammond C, Abdulla H, Entz A, et al. Clinical characteristics and morbidity associated with Coronavirus disease 2019 in a series of patients in metropolitan Detroit. JAMA Netw Open. 2020;3:e2012270.

25. Giri M, Puri A, Wang T, Guo S. Comparison of clinical manifestations, pre-existing comorbidities, complications and treatment modalities in severe and non-severe COVID-19 patients: a systemic review and meta-analysis. Sci Prog. 2021;104:368504211000906.

26. Martins-Filho PR, Araújo AS, Pereira LX, Quintans-Júnior LJ, Barboza WS, Calvacante TF, et al. Factors associated with mortality among hospitalized patients with COVID-19: a retrospective cohort study. Am J Trop Med Hyg. 2021;104:103-5

27. Andrade CL, Pereira CC, Martins M, Lima SM, Portela MC. COVID-19 hospitalizations in Brazil's Unified Health System (SUS). PLoS One. 2020;15:e243126.

28. Dalamaga M, Christodoulatos GS, Karampela I, Vallianou N, Apovian C. Understanding the co-epidemic of obesity and COVID-19: current evidence, comparison with previous epidemics, mechanisms, and preventive and therapeutic perspectives. Curr Obes Rep. 2021;10:214-43.

29. Demeulemeester F, de Punder K, van Heijningen M, van Doesburg F. Obesity as a risk factor for severe COVID-19 and complications: a review. Cells. 2021;10:933.
30. Gonçalves DA, Ribeiro V, Gualberto A, Peres F, Luconi M, Gameiro J. COVID-19 and obesity: an epidemiologic analysis of the Brazilian data. Int J Endocrinol. 2021;2021:6667135.

31. Brasil. Ministério da Saúde. Plano nacional de operacionalização da vacinação contra a COVID-19. 12ª ed, Brasília: Ministério da Saúde; 2022. [cited 2022 Jan 27]. Available from: https:// www.gov.br/saude/pt-br/coronavirus/publicacoes-tecnicas/ guias-e-planos/plano-nacional-de-operacionalizacao-davacinacao-contra-covid-19.pdf/

32. Choi KJ, Hong HL, Kim EJ. The association between mortality and the oxygen saturation and fraction of inhaled oxygen in patients requiring oxygen therapy due to COVID-19-associated pneumonia. Tuberc Respir Dis (Seoul). 2021;84:125-33.

33. World Health Organization. Clinical management of severe acute respiratory infections when novel coronavirus is suspected: what to do and what not to do. [cited 2022 Jan 27]. Available from: https://www.who.int/csr/disease/coronavirus_ infections/InterimGuidance_ClinicalManagement_ NovelCoronavirus_11Feb13u.pdf

34. Catoire $\mathrm{P}$, Tellier E, de la Rivière $\mathrm{C}$, Beauvieux MC, Valdenaire $\mathrm{G}$, Galinski M, et al. Assessment of the $\mathrm{SpO}_{2} / \mathrm{FiO}_{2}$ ratio as a tool for hypoxemia screening in the emergency department. Am J Emerg Med. 2021;44:116-20.

35. Malik P, Patel U, Mehta D, Patel N, Kelkar R, Akrmah M, et al. Biomarkers and outcomes of COVID-19 hospitalisations: systematic review and meta-analysis. BMJ Evid Based Med. 2021;26:107-8.

36. Gorman E, Connolly B, Couper K, Perkins GD, McAuley DF. Non-invasive respiratory support strategies in COVID-19. Lancet Respir Med. 2021;9:553-6.

37. Associação de Medicina Intensiva Brasileira. Comitê de Insuficiência Respiratória e Ventilação Mecânica. Uso de ventilação não invasiva (VNI) com pressão positiva no paciente com COVID-19. [cited 2022 Jan 27]. Available from: https:// www.amib.org.br/fileadmin/user_upload/12Uso_de_VNI_ com_Pressa_o_Positiva_na_COVID.pdf

38. Li J, Huang DQ, Zou B, Yang H, Hui WZ, Rui F, et al. Epidemiology of COVID-19: a systematic review and metaanalysis of clinical characteristics, risk factors, and outcomes. J Med Virol. 2021;93:1449-58.

39. El Aidaoui K, Haoudar A, Khalis M, Kantri A, Ziati J, El Ghanmi A, et al. Predictors of severity in Covid-19 patients in Casablanca, Morocco. Cureus. 2020;12:e10716.

40. Richardson S, Hirsch JS, Narasimhan M, Crawford JM, McGinn T, Davidson KW, et al. Presenting characteristics, comorbidities, and outcomes among 5700 patients hospitalized with COVID-19 in the New York City Area. JAMA. 2020;323:2052-9. 